\title{
La Biblioteca Ayacucho según Ángel Rama: debates, definiciones y balances
}

\author{
Facundo Gómez ${ }^{1}$ \\ Universidad de Buenos Aires-UBA, Argentina
}

Resumen: Durante su exilio en Venezuela, Ángel Rama dirige la Biblioteca Ayacucho, el proyecto editorial que busca compilar, revisar y publicar los textos clásicos de las letras y el pensamiento latinoamericano. El artículo explora el modo en que Rama concibe y pone en funcionamiento la casa editorial a través del examen un material de archivo compuesto por cartas, ensayos, entrevistas y ponencias inéditas. El proceso de edificación es lento, complejo y conflictivo. La revisión demuestra que el crítico uruguayo diseñó y construyó la Biblioteca Ayacucho como una herramienta de integración cultural, una red entre los intelectuales latinoamericanos exiliados y una empresa de revisión colectiva de la historia y la identidad de la región.

Palabras clave: Ángel Rama; Biblioteca Ayacucho; Literatura latinoamericana; Integración cultural; Redes intelectuales.

Título: A Biblioteca Ayacucho segundo Ángel Rama: debates e definições

Resumo: Durante seu exilio na Venezuela, Ángel Rama dirige a Biblioteca Ayacucho, o projeto editorial que busca compilar, revisar e publicar textos clássicos das letras e do pensamento latino-americano. Mediante a pesquisa do material do arquivo composto por cartas, ensaios, entrevistas e dissertações inéditas, o artigo explora a maneira por meio da qual Rama pensa e monta a editora. A revisão demostra que o critico uruguaio desenho e construiu a Biblioteca Ayacucho como uma ferramenta de integração cultural, uma rede entre os intelectuais latino-americanos no exilio e uma empresa coletiva de revisão da história e da identidade regional.

Palavras-chave: Ángel Rama; Biblioteca Ayacucho; Literatura latino-americana; Integração cultural; Redes intelectuais.

Title: Biblioteca Ayacucho according Ángel Rama: debates and definitions

Abstract: During his exile at Venezuela, Ángel Rama runs Biblioteca Ayacucho, a project aiming to compile, reassess and divulge classical texts of Latin American literature and thinking. The article explores how Rama visualizes and establishes the publishing house through the investigation of different archival materials, such as letters, essays, interviews and unpublished presentations. The development of the collection is gradual, difficult and conflictive. This research demonstrates that the Uruguayan critic designed and built Biblioteca Ayacucho as an instrument of cultural integration, a network of Latin American exiled intellectuals and a collective review of the regional history and identity.

Keywords: Ángel Rama; Biblioteca Ayacucho; Latin-American Literature; Cultural Integration; Intellectual networks.

\footnotetext{
${ }^{1}$ Licenciado y Profesor en Letras, Universidad de Buenos Aires-UBA. Orcid: https://orcid.org/00000002-2616-4834.
}

E-mail: gomezefacundo@gmail.com 
La figura del crítico uruguayo Ángel Rama constituye todo un ícono del intelectual latinoamericano de las décadas del 60 y 70. Su inmensa labor como lector, ensayista, investigador, docente y animador de la vida cultural de la región lo coloca en un lugar privilegiado para revisar una etapa fulgurante de nuestra historia intelectual. Sin embargo, a pesar de la evidente heterogeneidad de su praxis y del reconocimiento de sus pares y contemporáneos, hacia fines del siglo xx se trazó un recorte drástico sobre su producción. En gran parte debido a cierta agenda teórica fijada desde la academia norteamericana, la atención de los investigadores se concentró en los últimos libros de Rama y en los conceptos de transculturación narrativa y ciudad letrada. El conjunto entero de sus hipótesis e intervenciones previas (es decir, casi la totalidad de su trabajo como crítico literario e intelectual público) quedaron descartadas o subsumidas al enjuiciamiento de los dos términos. Este desaguisado se monta sobre una idea de Rama como puro teórico de la literatura, como reposado profesor de tiempo completo. Nada más lejos de la verdad.

Afortunadamente, esa imagen academicista de Rama se fue reformulando gracias a los aportes de nuevos enfoques y perspectivas, que supieron encontrar en su trayectoria un haz de prácticas culturales que articulan el ejercicio de la crítica literaria con otros modos del quehacer intelectual. En este sentido, su trabajo al frente de la Biblioteca Ayacucho condensa un haz de objetivos, ideas, cuestiones e intervenciones que dota de espesor y complejidad a su praxis. A la vez, su paso por la editorial venezolana nos ayuda a recomponer la historia de su proyecto intelectual que se reformula sin perder coherencia, que se concreta a pesar de las crisis y que avanza con una constante rearticulación de conceptos y estrategias.

Al cumplirse en 2019 los primeros cuarenta y cinco años de la fundación de la Biblioteca Ayacucho, en lo que sigue me interesa indagar en la manera en que Ángel Rama pensó y organizó la editorial desde su exilio venezolano, luego de su largo desempeño en el ámbito montevideano y de su ascenso como intelectual latinoamericano desde mediados de la década de 1960, gracias a su trabajo en el mítico semanario Marcha, su compromiso con Casa de las Américas, sus polémicas contra el intervencionismo estadounidense y su actualizada lectura de la exitosa narrativa contemporánea.

Un puñado de elementos biográficos y coyunturales resultan indispensables para comprender la iniciativa editorial montada en Caracas. El primero es su larga experiencia en el campo editorial, que data de la creación del sello artesanal Fábula en 1950 y alcanza su destacado desempeño al frente de Arca, la editorial que publica por primera vez a García Márquez y a Reinaldo Arenas en el Cono Sur y que emprende proyectos tan significativos para la cultura nacional como la Enciclopedia Uruguaya y los Bolsilibros (ROCCA, 2012; TORRES TORRES, 2012; GARCÍA LIENDO, 2017). El segundo, el distanciamiento con la política cultural cubana tras el caso Padilla, lo que implica para Rama la enunciación de un discurso menos pautado por el antiimperialismo furioso de la década anterior y una apuesta redoblada hacia un ideal de integración latinoamericana más allá de la mera confrontación 
ideológica. El tercer elemento es la ruptura pública con el llamado "boom" literario hacia 1972, tras la cual el crítico redescubre que la identidad de la región no se define por los últimos libros en boga, sino por una tradición literaria y cultural que se remonta siglos atrás y que incluye un archivo apenas explorado hasta entonces. Rama tiene la certidumbre de que hay un patrimonio en común que los agitados tiempos contemporáneos no han permitido ver con justeza y que bien vale la pena encarar una tarea de compilación, relectura y difusión de los textos clásicos que hacen a Nuestra América.

En un congreso en México, hacia 1972, el uruguayo plantea la necesidad de una editorial universitaria que se haga cargo de estas tareas (RAMA, 1972). La oportunidad llegará unos años más tarde, en tierras venezolanas. Por último, un fenómeno histórico regional se coloca como trasfondo trágico de la Biblioteca Ayacucho: la serie de golpes de Estado que asola América Latina y que impone sangrientos regímenes militares. La censura, la persecución, las torturas, las muertes y las desapariciones se convierten en macabra cotidianeidad y miles de exiliados abandonan sus patrias en busca de horizontes más propicios. Acontece una diáspora de sujetos que transportan consigo obras y sueños. Y la esperanza de reunirse y recuperar los proyectos en común interrumpidos por la barbarie militar.

\section{Una editorial latinoamericanista}

En un indispensable ensayo sobre el rol de Ángel Rama en la Biblioteca Ayacucho, Carlos Pacheco y Marisela Guevara (2003/2004) han reconstruido las condiciones económicas y políticas de Venezuela que hacen posible la fundación de la editorial. Entre ellos se destacan el boom petrolero y la colosal entrada de divisas a las arcas del Estado, los cambios demográficos en la ciudad de Caracas y el crecimiento en la demanda de bienes simbólicos por parte de sus habitantes. También, la llegada al poder de Carlos Andrés Pérez, quien despliega un ambicioso programa de desarrollo económico, una política exterior de entonación latinoamericanista y un destacado fomento a la cultura que se traduce en la fundación de la Biblioteca Ayacucho, Monte Ávila Editores, el teatro Teresa Carreño y el Centro de Estudios Rómulo Gallegos.

Aunque hasta el momento no se cuenta con una investigación exhaustiva que relate detalladamente los primeros pasos tras su fundación oficial, en una separata conmemorativa de la editorial se puede leer un testimonio manuscrito de José Ramón Medina, uno de los principales artífices de la Biblioteca Ayacucho. Allí, el poeta e intelectual venezolano cuenta que la primera idea sobre la posibilidad de compilar y publicar los clásicos de las letras latinoamericanas surge durante "una tarde de mucho coloquio con Ángel Rama", en la que ambos identifican la necesidad de contar con una colección que sirva de vehículo a la cultura latinoamericana y lamentan la interrupción de los proyectos encarados por ilustres predecesores como Rufino Blanco Fombona y Pedro Henríquez Ureña (apud BIBLIOTECA 
AYACUCHO, 2004, 74). Los intelectuales deciden entonces probar suerte y presentan a consideración del presidente un proyecto similar. Su nombre se inspira en la batalla final contra los españoles comandada por Antonio Sucre e intenta incorporarse a los festejos encarados por el Ejecutivo para celebrar el sesquicentenario del hito independentista

El boceto despierta el interés de las altas esferas del gobierno. La coyuntura económica favorable, la importancia dada a la celebración del aniversario y también la relevancia de una figura como Medina -quien no solo es un reconocido intelectual, sino que se desempeña como Fiscal General de la Nación-, juegan a favor del proyecto, que es aprobado en poco tiempo. Oficialmente, la Biblioteca Ayacucho se funda el 10 de septiembre de 1974 a través del decreto presidencial 407, que nombra los integrantes de la comisión ejecutiva que deben ponerla en marcha: José Ramón Medina, Ramón Escovar Salom, Simón Alberto Consalvi, Miguel Otero Silva, Ramón Velázquez, Oswaldo Trejo y Ángel Rama. Entre sus considerandos, el decreto puntualiza el sentido integrador que orienta a la editorial desde sus inicios, al señalar "Que se hace necesario poner en práctica un dispositivo que se oriente a mantener la vigencia del legado civilizador y colectivo de América y que sirva, igualmente, a manera de aglutinación dinámica de los intelectuales del Continente [...]" (PÉREZ, 1974, p. 126).

En la argumentación se transparentan las posiciones del crítico uruguayo, quien por esos mismos días brinda una entrevista a El Nacional y explica ciertas pautas de la editorial. Su primera definición acerca de la Biblioteca Ayacucho aborda la cuestión de la identidad regional: la colección de clásicos sirve como una demostración al mundo de la calidad y el dinamismo de una cultura regional que ha acumulado siglos de producción original. Luego, se remonta históricamente a los esfuerzos de Bolívar y de Martí por unir a los países del subcontinente y explica que las condiciones del mundo contemporáneo, tendiente a la conformación de bloques y grandes acuerdos comerciales, actualizan la secular aspiración latinoamericana (apud BRICEÑO, 1974).

El primer local de la Biblioteca Ayacucho es instalado en unas dependencias de la Procuraduría venezolana, a cargo de José Ramón Medina. Allí, en una oficina con un escritorio, un teléfono y su máquina de escribir, Ángel Rama da los pasos iniciales en la concreción de su gran proyecto latinoamericanista. El mismo no podía sino comenzar con el tendido de redes con los colegas intelectuales, a quienes el uruguayo prontamente reúne para diseñar las ideas rectoras de la Biblioteca Ayacucho. No existe ningún documento oficial con las exposiciones o las conclusiones de esa reunión o de las subsiguientes, celebradas en Caracas en 1975, 1976 y 1982. Sin embargo, es posible rastrear algunos indicios de los dos primeros encuentros a partir de testimonios, epistolarios y artículos de prensa. Respecto al datado en 1975, Noé Jitrik destaca el rol de Ángel Rama en la animación de las discusiones y el consenso acerca de las dos orientaciones que la editorial se proponía observar: la compilación en una única colección de las obras representativas de las diferentes culturas nacionales y la recuperación y preparación de textos coloniales de difícil acceso y restringida difusión (apud COELHO, 2003, p. 121). Por otro lado, tras la reunión, Medina brinda una 
conferencia de prensa en noviembre en la que socializa ocho puntos fundamentales de la Biblioteca Ayacucho: la recopilación del legado cultural de la región; la organización del catálogo a través de un trabajo colectivo e interdisciplinario; el carácter cerrado de la colección; la prevalencia de un criterio jerárquico que selecciona obras según su grado de realización; la centralidad de las obras literarias dentro de un vasto archivo intelectual; una definición de América Latina que incluye al sector hispánico, al Brasil y a las Antillas; una precavida reflexión a la hora de incorporar obras contemporáneas, ya que se busca poner en circulación productos poco difundidos por el mercado; la elección de un lector no académico, sino representado por el "promedio del público culto del continente"; por último, la celebración de encuentros periódicos de expertos que determinen cuáles son los pasos a seguir en la edición de libros (CLAUDIO, 1975, p. 22).

En su puesto de director literario de la Biblioteca Ayacucho, designado como tal por la comisión directiva compuesta por hombres de la cultura y la política venezolana y presidida por Medina, Ángel Rama escribe y firma cartas y documentos a granel. La correspondencia demuestra cómo se trazan los vínculos y se intensifica la comunicación con los intelectuales latinoamericanos dispersos por el mundo. Por ejemplo, en una carta del 25 de octubre de 1979, Rama le escribe al crítico Luis Harrs con el propósito de conseguir su colaboración para el volumen dedicado a Ricardo Güiraldes. Allí le explica cuáles son las normas que se deben cumplir para el diseño del libro, la paga y los plazos de entrega. Antes de despedirse, dedica algunas líneas sobre un ensayo de crítica literaria que el argentino parece haberle enviado con anterioridad. El uruguayo demuestra un interés sobre su contenido y le propone publicar el material en la revista Escritura, que él mismo funda y dirige desde 1976. Aunque menor, el dato es significativo porque torna visible la multiplicidad de redes que Rama tiende a la vez. Harrs le interesa como colaborador en la Biblioteca Ayacucho, pero también como interlocutor en la revista universitaria especializada en teoría y crítica literaria que funda en la Universidad Central de Venezuela, otra de sus aventuras en el exilio. La correspondencia se ramifica en función de una paciente, diversa y simultánea construcción de canales de comunicación entre los intelectuales de la región dispersos por el mundo. El de Harrs no es el único caso. Un rápido repaso por los nombres que aparecen en Biblioteca Ayacucho y en Escritura lo confirma. Noé Jitrik, Ricardo Gutiérrez Girardot, Antonio Cándido, Jorge Ruffinelli y Márgara Rusotto son solo algunos de los críticos involucrados tanto en la editorial como en la revista.

Este tipo de intercambio se verifica con otros pares, tal como se puede leer en un puñado de cartas de 1983. En ellas, se dirige a profesores como David Sobrevilla, a quien le escribe desde París. En carta del 30 de agosto de 1983, se explaya acerca de un informe enviado en torno a una posible compilación de ensayos del peruano José Basadre y se muestra muy entusiasmado por la calidad del trabajo, por lo que le propone colaborar en el tomo dedicado a la obra del historiador. Algo similar sucede con dos cartas remitidas a Carlos Monsiváis, en las que se connota un vínculo más amistoso y un tono más coloquial. Ambas tratan sobre la preparación de un volumen sobre el grupo intelectual "los Contemporáneos" 
e ilustran el modo en que Rama aprovecha los contactos ya establecidos con escritores para conseguir nuevos compromisos y colaboraciones. Luego de pedirle al mexicano noticias sobre el volumen encomendado, en la segunda carta, fechada el 8 de noviembre de 1983, el crítico solicita datos postales de Héctor Aguilar Camín, director de la revista Nexos, y de Carlos Blanco Aguinaga, intelectual español afincado en México. El objetivo es el mismo en ambas situaciones: solicitarles ayuda para la confección de tomos dedicados a la cultura del país, que juzga parcamente representado en el catálogo de los últimos años. Y de pasada, la misma carta hay un registro de la participación de Rama en otra red intelectual: la que se trama alrededor del proyecto de una historia de la literatura latinoamericana desde una perspectiva comparatista, cuyo encuentro más significativo se celebra en la Universidad de Campinas, bajo el auspicio de Antonio Candido. El crítico inicia su carta del 8 de noviembre de 1983 con las siguientes frases: "Beatriz Sarlo me entregó en Campinas tu carta, por la cual me entero que estabas en Buenos Aires cuando yo viajé a México. El desencuentro perfecto, en un continente demasiado grande" (RAMA, 1983). La mención a las distancias siderales que separan a los intelectuales de la región alude a una de las mayores dificultades de las épocas para el trabajo colaborativo y, a la vez, evidencia las distintas vías que se inventan para sortearlas; en este caso, el envío de cartas por terceros involucrados en otros proyectos, también solidarios con el ideal de la integración.

Rama no se contacta solamente con colegas, sino que también gestiona contratos con quienes poseen los derechos de edición de los autores ya fallecidos. Es lo que se observa en las cartas remitidas a Heloísa Ramos, la esposa del novelista nordestino Graciliano Ramos. En la primera de ellas, firmada en París el 24 de julio de 1983, presenta formalmente la editorial como una casa destinada a publicar a los escritores más importantes del subcontinente. Acompaña la definición de la Biblioteca Ayacucho con el monto y la forma de pago estipulada: se adelanta una cifra fija al momento de recibir el contrato firmado (mil dólares) y luego se retribuye con un diez por ciento del precio de tapa (que ronda los diez o quince dólares), liquidado de forma anual. Hacia el final se insiste con el carácter no comercial de la empresa y se acota que no se exige ninguna exclusividad de edición.

El interés en sumar los trabajos de Graciliano Ramos en la Colección Clásica plantea una revisión acerca de una de las principales cuestiones de la integración latinoamericana que es jerarquizada por el proyecto editorial venezolano: la debida y postergada inclusión de Brasil. El punto adquiere en el epistolario una importancia manifiesta, asentada sobre todo en el diálogo con Antonio Candido y Darcy Ribeiro. La publicación de la correspondencia intercambiada entre los tres intelectuales en dos libros, preparados por Pablo Rocca y Haydée Ribeiro Coelho (2015), permite recuperar los esfuerzos de Rama por traducir los textos clásicos de las letras latinoamericanas y darlas a conocer en el hemisferio de habla hispana. El aporte de los dos intelectuales brasileños resulta fundamental para cumplir con este objetivo.

El primero en ser contactado para participar de la Biblioteca Ayacucho es Antonio Candido, a quien Rama le comenta en 1974 sobre la creación de la comisión que da 
comienzo oficial al trabajo editorial. En carta del 17 de septiembre, el crítico señala los principales rasgos de la Biblioteca Ayacucho: una colección cerrada de trescientos números, que reúne los textos más importantes escritos en América Latina, entendida ésta en su conformación española, portuguesa y francesa, desde los tiempos precolombinos hasta la contemporaneidad (RAMA e CANDIDO, 2016, p. 70). Candido responde celebrando la idea y aceptando el ofrecimiento de Rama de sumarse a ella como asesor de la parte brasileña. Además, el crítico cumple con la solicitud de Rama de enviarle una lista con veinte títulos de las letras nacionales cuya presencia en la futura colección considera imprescindible (p.73).

Por su parte, el desempeño de Darcy Ribeiro en la Biblioteca Ayacucho justifica su consideración como el segundo pilar de la inclusión del Brasil en la editorial. En lo que pareciera ser la continuación de un diálogo iniciado anteriormente, el uruguayo le escribe el 25 de noviembre de 1975 y lo pone al tanto de las dificultades organizativas que surgen alrededor de la tentativa. Rama solicita una nómina de títulos representativos de las letras nacionales, como la que ya le había mandado Candido. Le propone además participar de la colección a través de la escritura de un prólogo que acompañe el tomo con la obra de Gilberto Freyre y mediante la publicación de su libro Las Américas y la civilización (RAMA et al, 2015, p. 63). La respuesta es afirmativa, aun aclarando que la única garantía de que se trata de un proyecto serio y no de un "desperdício típico caraquenho" (p. 65) es que cuenta con la dirección del crítico uruguayo. A partir de esta carta, el tema que atraviesa las siguientes es la demora de Ribeiro en el envío del prólogo prometido. A la vez, ambos intelectuales conversan sobre los avances y obstáculos en la confección de los volúmenes brasileños, particularmente en relación con la cesión de derechos, la preparación de estudios y cronologías y las traducciones al castellano.

\section{Las polémicas y las definiciones}

Más allá de las declaraciones en los medios venezolanos y las registradas en el epistolario, hasta 1980 Ángel Rama no escribe ningún texto programático sobre su visión personal de la Biblioteca Ayacucho. Sin embargo, las dificultades y los disensos al seno de la Comisión Directiva y los recelos de ciertas figuras emblemáticas de la cultura venezolana se acumulan con cada tomo que sale. El proceso alcanza un punto de inflexión hacia 1980. El episodio disparador transcurre en un almuerzo organizado en Caracas por institución para aprovechar la visita de Rama a país, quien por ese tiempo ya se encuentra instalado en Estados Unidos. Allí, el novelista Arturo Uslar Pietri formula una serie de críticas lacerantes a las principales políticas editoriales de la institución.

El intercambio resulta infausto. Días después, el uruguayo escribe una extensa carta a José Ramón Medina, fechada el 15 de febrero de 1980, en la que glosa y refuta uno por uno los argumentos del intelectual venezolano. Comienza con el reclamo de Uslar Pietri de que la Biblioteca Ayacucho debe publicar solo textos literarios, un asunto que Rama deplora 
amargamente, ya que, desde su punto de vista, el carácter interdisciplinario de la colección es una de las principales decisiones editoriales consensuadas por los expertos. La segunda queja del venezolano se vierte sobre la publicación de las obras históricas enunciadas durante la Conquista, lo que supone para él la inclusión de autores españoles que operan en favor de la opresión de los pueblos americanos. A Rama le parece un error garrafal excluir de la colección este conjunto de textos, cuya presencia pondera como "una línea central del proyecto". Para reforzar su apreciación sobre el valor de las crónicas de soldados, viajeros e historiadores, enumera los volúmenes en preparación y los esfuerzos extraordinarios que la tarea demanda y amerita con creces; por ejemplo, la primera transcripción completa de la obra de Huamán Poma de Ayala, sobre la que se viene trabajando desde hace años, y las investigaciones en las que el propio Rama se halla inmerso por ese entonces en la Biblioteca del Congreso, en Washington.

Otros dos señalamientos de Uslar Pietri apuntan sobre cómo son presentadas en la colección las obras de Simón Rodríguez y Simón Bolívar. La primera se considera demasiado acotada, mientras que la inclusión de algunas de reflexiones del Libertador en el tomo sobre el discurso conservador del siglo XIX que preparó José Luis Romero es percibida con desagrado. Rama explica que el poco espacio que los textos de Rodríguez ocupan en la antología responde a que se le reserva a su obra un volumen completo, cuya edición no es urgente porque hay en circulación todavía muchos libros universitarios sobre su figura. Sobre el lugar de Bolívar entre los exponentes del pensamiento conservador, se defiende la decisión de Romero por considerar que el prócer venezolano está representado en la colección a través de sus múltiples facetas y en tres volúmenes distintos. Uno es el tomo que le está íntegramente dedicado y que recoge su doctrina política más representativa. El segundo es el libro sobre la emancipación. El tercero es el que origina la polémica; su justificación es que incluye las reflexiones del Libertador sobre la constitución boliviana y recupera sus posicionamientos ante la anarquía y la desorganización de las jóvenes naciones americanas, en un impulso que no puede sino caracterizarse como conservador respecto a las procesos sociales y políticos en desarrollo.

Otro de los cuestionamientos de Uslar Pietri es que la Biblioteca misma no debería publicar textos cuya lengua original no sea el español o el portugués. La repuesta de Rama parte de una definición amplia de América Latina que ya no está cifrada en el lenguaje, sino en la cultura y la historia en común. La presencia en la colección de obras pertenecientes al Caribe inglés y francés es pensada como una estrategia fundamental para la integración de países que han atravesado experiencias históricas similares pero que todavía no se han logrado ser percibidos por la cultura del subcontinente como pares de igual jerarquía. Para ilustrar la importancia de esta intención, Rama se explaya sobre los tomos en preparación que buscan reparar esta falta. Nombra autores de interés para el catálogo (como Jean-PriceMars, Jacques Roumain, Jacques Stephan Alexis) y añade que se están estudiando las literaturas jamaiquinas $\mathrm{y}$ trinitenses para poder traducir y publicar sus textos más representativos. 
El último reparo glosado es el que reviste un carácter más nacionalista y consiste es exigir una mayor presencia de autores venezolanos. El crítico uruguayo brinda aquí una explicación relevante sobre el orden de aparición de los textos, que no responde ni a un plan prefijado ni a una ponderación jerárquica. Los tomos de la Biblioteca Ayacucho, en primer término, son producidos según una distribución de títulos por nación y, luego, a medida que los originales son adquiridos y que los responsables entregan las compilaciones, prólogos y cronologías. Así, la cantidad de libros por país depende, según Rama, de la capacidad de equipos intelectuales y la disponibilidad de textos originales. Esas son las razones por las cuales las letras y el pensamiento peruano cuentan con una mayor representación en la editorial en relación con las obras venezolanas.

Su comentario finaliza con una opinión condescendiente acerca de este tipo de reproches. Según Rama, gran parte de estas críticas tienen que ver con el apresuramiento y la impaciencia: la ausencia transitoria de varios de los grandes clásicos nacionales responde simplemente a los tiempos de preparación de los volúmenes. El párrafo final de la carta, en cambio, echa luces sobre el grado de compromiso personal de Rama con la empresa y el modo agonístico con que asume las críticas de Uslar Pietri: tras la detenida refutación pone a disposición de la Comisión Directiva su renuncia como director literario en el caso de que los principios editoriales expresados no fueran compartidos por los responsables últimos de la fundación. El carácter dramático de su decisión es captado por José Ramón Medina, quien contesta desde Caracas y le manifiesta a Rama su total respaldo a sus labores en la fundación. En carta del 7 de marzo de 1980 sentencia en nombre de toda la comisión que no hay razones para cambiar las políticas editoriales ni mucho menos para que el uruguayo renuncie a su cargo. La demostración da resultados, porque el crítico continúa en su puesto y redobla su apuesta por las posibilidades culturales de una empresa como Biblioteca Ayacucho.

De todas maneras, la confrontación con Uslar Pietri afecta notablemente a Rama, tal como queda registrado en la entrada de su diario del 6 de marzo de 1980, cuando intuye con dolor y escepticismo que su alejamiento de Venezuela amenaza el destino de la editorial (RAMA, 2008, p. 200). Sin embargo, el episodio no lleva al mero desasosiego, sino que opera como un catalizador de ideas, balances, definiciones y propuestas. El resultado es el único ensayo que Ángel Rama escribe sobre el diseño y sentido de la Biblioteca Ayacucho, publicado el año siguiente a la discusión con Uslar Pietri. Desde su título, se torna evidente que se trata de un texto programático, que define de forma tajante el sentido de la empresa venezolana: se denomina "La Biblioteca Ayacucho como instrumento de integración cultural latinoamericana" (2004) y sirve como una declaración de principios y aspiraciones, firmada a posteriori.

El texto se inicia con una frase que marca desde qué perspectiva ideológica se sitúa Rama para describir la editorial: "La integración cultural es fundamento y legitimación de los diversos proyectos de integración económica o política que se han venido diseñando en América Latina" (RAMA, 2004, p. 63). Su inserción respecto a su trayectoria nos confirma 
cambios y reinvenciones en su praxis y en su figura como intelectual. El más notorio es el progresivo alejamiento respecto a las posiciones militantes antiimperialistas más beligerantes de la década de 1960, cuando piensa a la literatura latinoamericana como un registro de las fracturas sociales y de las transformaciones políticas del subcontinente.

En el texto revisado, la Biblioteca Ayacucho es concebida en términos temporales que parecen inspirarse en las tesis de la filosofía de la historia de Walter Benjamin, el pensador alemán que tanto influye en las ideas de Rama sobre la literatura y la cultura desde fines de la década de 1960. En el ensayo se lee: "En estas condiciones, el pasado no es recuperado en función de archivo muerto, sino como un depósito de energías vivientes que sostienen, esclarecen y justifican el proceso de avance y transformación revolucionaria" (2004: 63). Esta idea de una colección que mira a la vez al pasado y al futuro es uno de los ejes de la propuesta de Rama, lo que se percibe de forma prístina en la atención puesta sobre el archivo colonial y sobre la misma editorial como cimiento cultural de una integración política y económica todavía pendiente. Rama indica que los dos obstáculos que la Biblioteca Ayacucho busca subsanar son el desconocimiento de textos fundacionales y la adopción acrítica de modelos críticos importados propias de los años recientes. Operar en dos tiempos a la vez, en el archivo pleno de significaciones y en el presente saturado de conflictos, es la cifra temporal sobre la que se asienta su diseño, a la cual se suma otra, de carácter cultural: la exigencia de que la integración del subcontinente a la modernidad capitalista no debe hacerse en desmedro de las culturas interiores. Articular los polos internos y externos de la creación latinoamericana es el otro eje de la Biblioteca Ayacucho.

Al momento de las definiciones, Rama enuncia explícito sobre ella: "Fue concebida inicialmente como una biblioteca cerrada cifrada en unos quinientos tomos, que recogiera la vigencia del legado civilizador de América Latina..." (2004, p. 70). Agrega además que los textos han sido seleccionados y preparados según tres criterios centrales. El primero es calificado por Rama como "culturalista" y es lo que distingue a la empresa de otras anteriores. Se trata de una amplia y rica apertura genérica, que compila, junto a la poesía, la narrativa y el teatro, diversas textualidades, como ensayos, cartas, crónicas, relatos orales, proclamas y manifiestos. El segundo criterio es sociológico y apunta a dotar a la colección de un espesor social, respetuoso de la heterogeneidad de materiales, fuentes y enunciadores. Rama señala la importancia de presentar a los lectores una visión de la cultura latinoamericana que vaya más allá del corpus producido por la elite letrada y que integre la expresión y la crítica de los sectores más oprimidos y marginados de la sociedad. El último criterio de la Biblioteca Ayacucho es la inclusión de obras que no han sido escritas por autores latinoamericanos, pero que sin embargo son imprescindibles para pensar la identidad regional, a la que enriquecen con inquietudes, perspectivas y estilos. Esta propuesta supone entender la cultura del subcontinente como un producto híbrido que surge en el encuentro conflictivo de tradiciones propias y ajenas. Así queda desmontado el esencialismo geográfico como posible criterio de selección y, además, se coloca a la ficción literaria como un factor central en la historia de cada uno de los países. Por ejemplo, Rama 
sugiere que tanto las cartas de Humboldt como las novelas de Hudson merecen ser incluidas en la colección como una "huella formativa" en el devenir de la cultura latinoamericana. La operación marca una innovación inédita en su manera de pensar la cultura latinoamericana, conformada ahora también por la mirada externa.

El ensayo finaliza con una reflexión sobre los diversos niveles de integración de la Biblioteca Ayacucho, lo que implica fijar sentidos acerca de esta noción, central en su discurso y en su praxis. La integración latinoamericana involucra aspectos que van desde la creación de un discurso crítico unificador hasta la incorporación de áreas culturales usualmente dejadas de lado en los estudios sobre literatura y pensamiento latinoamericano. Rama jerarquiza aquí una de las operaciones de la Biblioteca Ayacucho: la inclusión de Brasil en el catálogo, tal como ha sido analizado anteriormente. Su exclusión no es la única que la Biblioteca busca subsanar. Rama indica también el caso de Puerto Rico, escindido de las redes culturales latinoamericanas debido a su particular estatus político. Su ausencia recurrente en panoramas y estudios busca ser enmendado con la edición de varios libros representativos de esta cultura nacional, dos de los cuales ya han sido publicados por la editorial (La charca, de Zeno Gandía, y la Poesía completa de Luis Palés Matos). Otro de los fenómenos de fragmentación regional que busca ser revertido son los casos de las literaturas del Caribe expresadas en lengua inglesa, francesa y holandesa.

Resta el examen de otro tipo de fenómenos que Rama pondera como uno de los objetos privilegiados para la realización del imperativo integrador: la existencia de eventos históricos, corrientes de pensamiento y movimientos estéticos que atraviesan las fronteras y que conectan las escenas nacionales bajo un mismo impulso intelectual. El crítico cita dos tomos que representan este tipo de procesos en la colección: el dedicado al pensamiento de la emancipación, preparado por José Luis Romero, y el que recoge los textos principales del positivismo, a cargo de Leopoldo Zea. Rama enuncia el sentido y también la dificultad que supone esta precisa tarea: "Esta línea de volúmenes que realizan, prácticamente, el principio de integración de la cultura latinoamericana, no es de fácil realización. Aún se cuenta con escasos estudiosos capaces de visiones conjuntas, documentadas y solventes" (RAMA, 2004, p. 85).

La formación de equipos intelectuales es uno de los objetivos primordiales de la Biblioteca Ayacucho para Rama. Hacia mediados de la década de 1970, la posibilidad de financiar el trabajo de los escritores y pensadores dispersos por el mundo excede los requerimientos meramente eruditos de la empresa y opera como un certero acto de solidaridad hacia quienes habían sido perseguidos en sus países o expulsados más allá de sus fronteras por el autoritarismo militar y la violencia política. Por lo tanto, Ángel Rama, en tanto exiliado sudamericano e intelectual atento a las urgencias de la época, trabaja al interior de la editorial estatal no solo para promover la cultura de América Latina y revisar su visión del pasado, sino para unir y ayudar a sus colegas en la diáspora. Se busca reinventar, desde otra instancia enunciativa, un proyecto latinoamericanista utópico, dramáticamente modificado por la historia y refundado con tesón en la nación de Bolívar. 


\section{Balances y perspectivas}

El ensayo analizado no es el último texto que Rama escribe respecto a la Biblioteca Ayacucho. Entre sus papeles personales se ha encontrado una ponencia sin nombre, presumiblemente formulada para su exposición en un encuentro académico organizado por la UNESCO en París hacia 1983. Según lo señalan Carina Blixen y Alvaro Barros-Lémez, se trata del coloquio "Littérature et Pensées contemporaines en Amérique Latine et aux Caraïbes: conservation, diffusion et éditions critiques des manuscrits" (1986, p. 65). Su lectura funciona como un balance hasta ahora inédito acerca de lo logrado, lo frustrado y lo postergado en la Biblioteca Ayacucho tras la publicación de su primer centenar de tomos.

La ponencia se propone repasar ciertos lineamientos implícitos que habían guiado hasta entonces la tentativa. Al inicio, reconoce el apoyo del Estado nacional venezolano por el efectivo financiamiento económico y la libertad para trabajar sin condicionamientos ideológicos. Luego, se explaya sobre lo que considera los cinco rasgos distintivos de la Biblioteca Ayacucho. El primero es su concepción como biblioteca y no como una antología de libros antiguos y modernos. Respecto de esta idea, la figura de referencia es Pedro Henríquez Ureña y su Biblioteca Americana, tal ha sido estudiado en detalle por Marcela Croce (2015). Rama celebra el legado del dominicano para enseguida marcar un disenso entre su proyecto y el actual en curso; este último no cuenta con un plan minucioso de publicaciones, sino que el catálogo se confecciona según lo pauta el consenso de latinoamericanistas, reunidos con cierta periodicidad para debatir y decidir inclusiones y exclusiones. El crítico vuelve así a lo afirmado en las primeras entrevistas sobre el emprendimiento y la importancia de una selección colectiva de materiales, atenta a la lectura del pasado remoto desde el presente más urgente. Se delinea también en su exposición el funcionamiento más básico de la editorial, consistente en la articulación entre una vasta red de asesores y colaboradores y un equipo ejecutor que centraliza los aportes y los adecúa a las exigencias de la colección.

El segundo rasgo de la Biblioteca Ayacucho, sentencia Rama, es su carácter cerrado, que consta de un número impreciso, pero cercano a los quinientos tomos. El sentido de esta característica es subrayar la tarea de juicio crítico que se debe efectuar sobre las obras, de forma tal de representar adecuadamente movimientos intelectuales, procesos históricos y autores de relevancia. El tercer rasgo es la elección del criterio "culturalista" en la construcción de la editorial. El asunto, ampliamente desarrollado en el ensayo de 1980 insiste en la apertura genérica implicada en esta definición. Lo significativo del punto es que mientras Rama celebra la futura publicación de obras que han sido forjadas por fuera de la "ciudadela culta", sobrevive en su pensamiento una jerarquización sin mácula de las disciplinas y tradiciones culturales propias de los estratos cultos y urbanos: "Junto a la literatura, la historia, la filosofía, que constituyen las vigas maestras de la producción intelectual, se buscó incorporar el arte, el folklore, la antropología, la arquitectura, la economía, la música, etc...." (1983, p. 3, cursivas propias). La fe en el humanismo letrado y 
sus productos seculares, presente en todos los textos hasta aquí analizados, se mantiene intacta en su perspectiva crítica, a pesar de estar formulando simultáneamente hacia esta época la aparente diatriba contra los intelectuales que es La ciudad letrada, su libro póstumo.

El cuarto rasgo es la integración, un elemento constitutivo del proyecto, desde la primera conversación de Rama con Medina. El uruguayo vuelve aquí sobre el problema de la incomunicación entre países de América Latina y explicita dos aspectos de la propuesta. Lo que se intenta unir son "sociedades nacionales", lo que demuestra que, más allá de sus razonamientos sobre áreas culturales, el Estado-nación es la unidad conceptual básica sobre la que se construye el catálogo de la Biblioteca Ayacucho. El otro aspecto de la integración es que responde a un estímulo externo, consistente en la mundialización de la economía y la cultura capitalista, frente a la cual los intelectuales latinoamericanos reaccionan aceptando del proceso, pero resguardando las peculiaridades culturales y trabajando para transformarlas en nuevos productos estéticos e instrumentos epistemológicos.

El quinto y último rasgo descrito en la ponencia aborda las cuestiones de tipo editorial que se debieron superar para la elaboración de la Biblioteca Ayacucho. Una de ellas fue la dificultad para normalizar y fijar las versiones definitivas de muchas obras literarias de la Colonia, lo que explica por qué aún en 1983 no había salido publicado ningún tomo con las obras de Sor Juana Inés de la Cruz. Rama se lamenta así por la ausencia de especialistas capaces de asumir la tarea de enmendar la edición de la Obras Completas preparadas por Alfonso Méndez Plancarte. Otro problema es la dispersión de una monumental cantidad de textos de grandes escritores del subcontinente que desplegaron una sostenida actividad periodística y cuyos artículos para la prensa se han mantenido al margen de las compilaciones y antologías. Una situación análoga padecen los materiales escritos en épocas de la Colonia y la Emancipación: los originales se hallan perdidos y desperdigados por las bibliotecas y archivos del mundo, por lo que su recuperación y publicación espera todavía la intervención de equipos profesionales probos e instituciones comprometidas.

Las conclusiones incluyen aciertos, deudas y derrotas. Entre los proyectos en preparación, Rama refiere la idea de abrir al seno de la Biblioteca Ayacucho una nueva colección de libros de bolsillo, con tiradas masivas y precios populares, al estilo de los "bolsilibros" de Arca. Rama afirma que la inminente salida de la nueva serie es una reafirmación de los grandes logros alcanzados por la editorial en términos de eficacia organizativa y reconocimiento de la crítica y el público. Otra idea sobre la que se explaya en la ponencia es la elaboración de una cronología general de América Latina, concebida tras las decepcionantes experiencias con las líneas de tiempo encargadas a los prologuistas de los libros clásicos, quienes demostraron en muchos casos carecer de un manejo riguroso y objetivo de datos históricos. En los dos casos, el crítico no llega a contemplar la concreción de sus dos proyectos: el primer volumen de la colección "Claves de América" es publicado en 1991 y la Cronología. Latinoamérica y el mundo aparece en 1987.

El mayor objetivo alcanzado por la Biblioteca Ayacucho, según su ponencia, es la 
inclusión definitiva de la cultura brasileña en una colección concebida programáticamente como latinoamericana. Lo mismo sucede respecto de los volúmenes dedicados a las literaturas indígenas. Sin embargo, se indica como un obstáculo aún no superado la integración del Caribe no hispánico. La observación marca a las claras la tensión entre la idea defendida con tesón por Rama y la imposibilidad de llevarla a cabo por razones instrumentales y prácticas.

\section{A modo de conclusión}

Para concluir, se puede decir la lectura de los textos de Ángel Rama sobre Biblioteca Ayacucho y la reconstrucción de su trabajo como editor nos permite pensar la Colección Clásica como un proceso en transformación y no como la mera realización de un canon intemporal impuesto por él mismo o un conjunto de expertos. Más bien, su paciente edificación supone una serie de esfuerzos, intercambios, debates y tensiones entre una multitud de especialistas, editores y funcionarios; una gestión cotidiana sostenida desde diversos puntos geográficos por una amplia red intelectual; un progresivo rediseño del catálogo según posibilidades materiales y reformulaciones conceptuales; la revisión crítica de sus defectos y limitaciones y una incesante creatividad respecto a sus proyectos e intervenciones futuras.

Su concreción implica para la praxis de Ángel Rama una experiencia trascendente, que aprovecha las lecciones históricas y culturales de la década de 1960 y condiciona un ejercicio crítico cada vez más interesado en el pasado secular latinoamericano. Visto en perspectiva, idear, dirigir, definir, pensar y realizar la Biblioteca Ayacucho se constituye como la gran aventura latinoamericanista de su vida. En sus tomos de tapas negras persiste el legado material e indeleble de un proyecto que supo activar aquel sueño de la integración regional de Bolívar, Martí y Henríquez Ureña que Rama retoma y adopta como misión, deber, orientación y utopía colectiva.

\section{Referencias}

BARROS-LÉMEZ, Á.; BLIXEN, C. Cronología y bibliografía de Ángel Rama. Montevideo: Arca, 1986.

BIBLIOTECA AYACUCHO. 30 años de Biblioteca Ayacucho. Caracas: Biblioteca Ayacucho.

BRICEÑO, J. H. El legado cultural que América Latina le ha dado al mundo contendrá la Biblioteca Ayacucho. El Nacional, p. D-9, 12 sep. 1974.

CANDIDO, A. Lucidez americana. Casa de las Américas, La Habana, a. XXXIV, n. 192, p. 14-15, 1993.

CLAUDIO, I. Ambicioso plan de publicaciones realizará la Biblioteca Ayacucho. El Universal, Caracas, p. 22, 8 nov. 1975. 
COELHO, H. R. Memorias de la memoria: el exilio de Darcy Ribeiro en Uruguay. Entrevistas. Belo Horizonte: Universidad Federal Minas Gerais, 2003.

CROCE, M. La comunidad imaginada del canon vernáculo. La seducción de lo diverso. Buenos Aires: Interzona, 2015. p. 93-106.

GARCÍA LIENDO, J. El intelectual y la cultura de masas. Argumentos latinoamericanos en torno a Ángel Rama y José María Arguedas. Indiana: Purdue University, 2017.

MEDINA, J. R. Carta a Ángel Rama. Caracas, 7 mar. 1980. Archivo Ángel Rama.

PACHECO, C.; GUEVARA, M. Ángel Rama, la cultura venezolana y el epistolario de la Biblioteca Ayacucho. Estudios, Caracas, 22/23, p. 99-116, 2003/2004.

PÉREZ, C. A. (1974). Después de los 100 días. Decretos del Presidente Carlos Andrés Pérez. Caracas: Centauro.

RAMA, Á. "Diez tesis sobre integración cultural en América Latina". In: II CONFERENCIA LATINO AMERICANA DE DIFUSIÓN CULTURAL Y EXTENSIÓN UNIVERSITARIA. México: Universidad Autónoma de México, febrero de 1972.

RAMA, Á. Carta a Carlos Monsiváis. París, 8 nov. 1983. Archivo Ángel Rama. https://doi.org/10.18356/76b2a66d-en

RAMA, Á. Carta a David Sobrevilla. París, 30 ago. 1983. Archivo Ángel Rama. https://doi.org/10.18356/76b2a66d-en

RAMA, Á. Carta a Heloísa Ramos. París, 24 jul. 1983. Archivo Ángel Rama.

https://doi.org/10.18356/76b2a66d-en

RAMA, Á. Carta a José Ramón Medina. Caracas, 31 dic. 1978. Archivo Ángel

RAMA, Á. Carta a José Ramón Medina. Washington, 15 feb. 1980. Archivo Ángel Rama.

RAMA, Á. Carta a Luis Harrs. Washington, 25 oct. 1979. Archivo personal Ángel Rama.

RAMA, Á. Diario 1974-1983. El Andariego-Trilce: Buenos Aires-Montevideo, 2008.

RAMA, Á. et al. Diálogos latino-americanos. Correspondência entre Ángel Rama, Berta e Darcy Ribeiro. Organización, estudios y notas de Haydée Ribeiro Coelho y Pablo Rocca. São Paulo: Global Editora, 2015.

RAMA, Á. La Biblioteca Ayacucho como instrumento de integración cultural latinoamericana. IN: 30 años de Biblioteca Ayacucho. Caracas: Biblioteca Ayacucho, 2004. p. 63-93.

RAMA, Á. Ponencia sin sombre sobre Biblioteca Ayacucho. Copia mecanografiada, circa 1983. Archivo Ángel Rama.

RAMA, Á.; CANDIDO, A. Un proyecto latinoamericano. Antonio Candido y Ángel Rama, correspondencia. Edición, prólogo y notas de Pablo Rocca. Montevideo: Estuario, 2016.

ROCCA, P. Ángel Rama, Emir Rodríguez Monegal y el Brasil: dos caras de un proyecto latinoamericano. Montevideo: Banda Oriental, 2006. 